\title{
EFFECTS OF FLORAL RESOURCES ON FITNESS OF THE LEAFROLLER PARASITOID (DOLICHOGENIDEA TASMANICA) IN APPLES
}

\author{
N.A. IRVIN ${ }^{1}$, S.D. WRATTEN ${ }^{1}$, R.B. CHAPMAN ${ }^{1}$ \\ and C.M. FRAMPTON ${ }^{2}$
${ }^{1}$ Ecology and Entomology Group, P.O. Box 84, Lincoln University, New Zealand ${ }^{2}$ Applied Computing, Mathematics and Statistics Group, P.O. Box 84, Lincoln University, New Zealand

\begin{abstract}
Leafrollers (Lepidoptera: Tortricidae) are major pests of pipfruit, largely because of the zero tolerance of their presence in, and damage to export fruit. A field trial was carried out in an apple orchard in Canterbury, New Zealand, to determine the influence of planting coriander (Coriandrum sativum L.) and buckwheat (Fagopyrum esculentum Moench.) on parasitism rates of leafrollers by Dolichogenidea tasmanica (Hymenoptera: Braconidae). Coriander (mean $=0.36$ cocoons $/$ shelter sites) significantly enhanced the parasitism rate compared with the herbicide-treated control (0.13). Buckwheat (0.21) had a similar but non-significant effect. The influence of floral resources on parasitoid longevity was evaluated in the laboratory. Parasitoids reared on a honey/water solution had the greatest longevity. A combination of buckwheat and coriander resulted in greater parasitoid longevity compared with either plant species alone. Incorporating flowering plants, such as coriander and buckwheat in the orchard understorey as part of an Integrated Fruit Production programme, may contribute to leafroller biocontrol by enhancing the abundance and longevity of their parasitoids.
\end{abstract}

Keywords: leafroller, parasitoid, floral resources, habitat manipulation, longevity.

\section{INTRODUCTION}

Leafrollers (Lepidoptera: Tortricidae) are major pests of pipfruit in New Zealand mainly due to the zero tolerance of their presence in export markets and the high requirement for blemish-free fruit (Wratten et al. 1998). Natural enemies of leafrollers have not proved effective in commercial orchards because the high use of insecticides kills them and frequent herbicide use has removed the plants which could provide the habitats, pollen and nectar resources required by many (Landis et al. in press).

The first priority of ENZAFRUIT New Zealand is to promote non-chemical methods of arthropod pest and plant disease control, to achieve a reduction in pesticide usage (Wratten et al. 1998). ENZAFRUIT and The Horticultural and Food Research Institute of New Zealand Ltd (HortResearch) have developed and introduced an integrated fruit production programme for pipfruit (IFP-P) (Batchelor et al. 1997). The insect growth regulator tebufenozide ('Mimic') is an important component of IFP and is replacing organophosphorous insecticides for leafroller control in New Zealand orchards (Wratten et al. 1998). As it selectively targets caterpillar pests and has little direct effect on natural enemies (Walker et al. 1991), it could therefore allow the enhancement of parasitoid populations. This would be desirable as leafroller resistance to tebufenozide has already occurred in New Zealand (Wearing 1998). Further information is still required on the role and management of the orchard understorey to enhance parasitoids (Batchelor et al. 1997). 
Buckwheat (Fagopyrum esculentum Moench.), which has small white flowers and shallow corollae, can provide pollen and nectar to a wide range of beneficial insects (Lovei et al. 1993) including short-tongued parasitoids. By comparison, floral nectar of broad bean (Vicia faba L.) is probably inaccessible to short-tongued parasitoids; however, a rich assemblage of ichneumonids attends extrafloral nectaries of this plant (Bugg et al. 1989). Irvin et al. (in press) showed that buckwheat, and to a lesser extent broad bean, significantly enhanced parasitoid numbers compared with the control (herbicide-treated understorey). They also found that parasitoid abundance was more than six-fold higher in a 'buckwheat with flowers' treatment compared with one with no flowers. However, the effect of flowers on parasitoid behaviour and fitness is unknown. This research aims to determine whether buckwheat and coriander sown in the orchard understorey will enhance leafroller parasitism by D. tasmanica and whether various floral resources influence $D$. tasmanica longevity in the laboratory.

\section{Understorey management}

\section{METHODS}

Five replicates of each of three treatments (buckwheat (Fagopyrum esculentum Moench.), coriander (Coriandrum sativum L.) and a herbicide-treated control) were set up in a randomised block design in an apple orchard at Lincoln University, Canterbury, New Zealand. Each replicate was $8 \mathrm{~m}$ long and consisted of 8-year-old apple trees (cvs. Braeburn, Royal Gala and Cox's Orange). Buckwheat (Fagopyrum esculentum Moench., cv. 'Shinano Natsu') and coriander (Coriandrum sativum L. var. microcarpum) seeds were sown on December 9, 1997 and resown on January 28, 1997 and January 9, 1997 respectively to ensure continuous flowering. In these plots, $5 \mathrm{~cm}$ wide strips of buckwheat or coriander were sown each side of the trees at a density of 2 seeds/cm. After 5-6 weeks (mid-January), flowering began and leafroller release started. Batches of approximately 200 lightbrown apple moth, Epiphyas postvittana (Walker) eggs, laid on sheets of paper, were placed on an apple branch in the centre of each plot on January 15, January 28, February 10 and February 25. Nylon mesh open-ended sleeves, which covered the release branches, were removed after 2-5 days, leaving the larvae exposed to parasitoids. The branches were collected 6-8 weeks after egg placement and the numbers of parasitoid cocoons and webbed leafroller shelters were recorded. Parasitism rate was expressed as the proportion of parasitoid cocoons/ webbed shelter and log-transformed to normalise distributions prior to analysis. Means are back-transformed in the text and table. ANOVA for repeated measures was used to compare treatment and time effects.

\section{Effect of food sources on parasitoid longevity}

Five replicates of six treatments (water, 50:50 honey/water solution, buckwheat (Fagopyrum esculentum Moench.), broad bean (Viciafaba L.), coriander (Coriandrum sativum L.) and buckwheat/coriander) were set up in a randomised block design under a 16:8 D photoperiod, at $20^{\circ} \mathrm{C}$. The water and honey/water treatments were contained in a $4 \mathrm{~cm}$ vial filled and sealed with a cotton wool plug. A water vial was placed in each treatment to prevent dehydration. Plant treatments consisted of a $5 \mathrm{~cm}$ length of flowering stem(s) placed in a $4 \mathrm{~cm}$ water-filled vial and sealed with a cotton wool plug. All treatments were topped up with water or honey/water solution as necessary, however, plant material was not replaced. Vials were covered with a cylindrical acetate sheet with netting glued on one end. A pair of newly-emerged adult D. tasmanica was placed in each treatment. The number of days until death of the parasitoid was recorded for both individuals. Survival curves were compared between treatments using log rank test and Kaplan Meier estimates of mean survival were calculated (Kaplan and Meier 1958).

\section{Understorey management}

\section{RESULTS}

There was a significant $(\mathrm{F}=4.884, \mathrm{df}=2,8, \mathrm{P}<0.05)$ difference in parasitism rate between the three flowering treatments over all dates and no interaction between treatment and time $(\mathrm{F}=0.637, \mathrm{df}=4,22, \mathrm{P}>0.05)$. Parasitism rate was significantly 
$(\mathrm{P}<0.05)$ higher in the coriander treatment (mean $=0.36$ cocoons/shelter site) compared to the control (0.13). Buckwheat (0.21) also enhanced parasitism rate compared with the control, however this was not significant $(\mathrm{P}>0.05)$.

\section{Effect of food sources on parasitoid longevity}

The water-only treatment resulted in the shortest longevity of both female and male $D$. tasmanica and was significantly $(\mathrm{P}<0.05)$ lower than all other treatments (Table 1). Survival in the honey/water treatment was significantly (female, $\mathrm{X}^{2}=4.268$, $\mathrm{df}=1, \mathrm{P}<0.05 ;$ male, $\left.\mathrm{X}^{2}=5.841, \mathrm{df}=1, \mathrm{P}<0.05\right)$ greater than in the coriander treatment for both female and male $D$. tasmanica. No other treatment combinations differed significantly $(\mathrm{P}>0.05)$ for female $D$. tasmanica. However, for males the honey/water treatment $($ mean $=21.1$ days $)$ also gave a significantly $\left(\mathrm{X}^{2}=5.093, \mathrm{df}=1, \mathrm{P}<0.05\right)$ greater longevity than did buckwheat (10.2) (Table 1). Combining buckwheat and coriander gave a significantly (buckwheat, $\mathrm{X}^{2}=10.69$, $\mathrm{df}=1, \mathrm{P}<0.001$; coriander, $\mathrm{X}^{2}$ $=4.66, \mathrm{df}=1, \mathrm{P}<0.05)$ higher longevity than that for buckwheat and coriander alone, for male D. tasmanica (Table 1).

TABLE 1: Mean longevity (days) for male and female $D$. tasmanica provided with different food sources in the laboratory at $20^{\circ} \mathrm{C}$.

\begin{tabular}{lcc}
\hline Floral treatment & Female & Male \\
\hline Water & $4.8 \mathrm{a}^{1}$ & $6.0 \mathrm{a}$ \\
Coriander & $8.7 \mathrm{ab}$ & $10.7 \mathrm{~b}$ \\
Buckwheat & $12.0 \mathrm{bc}$ & $10.2 \mathrm{~b}$ \\
Broad bean & $18.8 \mathrm{bc}$ & $20.5 \mathrm{bc}$ \\
Buckwheat/coriander & $19.6 \mathrm{bc}$ & $19.5 \mathrm{c}$ \\
Honey/water & $22.5 \mathrm{c}$ & $21.1 \mathrm{c}$ \\
\hline
\end{tabular}

${ }^{1}$ Means followed by same letter are not significantly different $(\mathrm{P}>0.05)$.

\section{DISCUSSION}

More than twice the rate of parasitism occurred in the coriander plots compared with controls suggesting that coriander shows potential for enhancing leafroller parasitism in apple orchards. The introduction of the insect growth regulator tebufenozide into integrated fruit production programmes has improved opportunities for the use of natural enemies for leafroller control (Wratten et al. 1998).

Although buckwheat did not have a significant effect on parasitism rate in this study, Stephens et al. (1998) found higher levels of parasitism in buckwheat plots than in controls and higher numbers of $D$. tasmanica were captured on yellow sticky traps in buckwheat plots. Also, Irvin et al. (in press) found more than seven times as many leafroller parasitoids in the buckwheat plots compared with controls and showed that buckwheat significantly enhanced leafroller parasitism by up to $68 \%$. The differences between studies may be accounted for by the differences in method of leafroller release and the techniques used for calculating parasitism rate. For instance, different leafroller release densities, sleeve types and leafroller developmental stages may have affected establishment. Irvin et al. (in press) used 'cocoons/cocoons+leafroller larvae+pupae recovered' as a measure of parasitism rate whereas the current study used 'cocoons/shelter sites', therefore influencing the calculated parasitism rate. The high dispersal of leafroller larvae (Penman 1984) will tend to make recovery of parasitoid cocoons from the release sites variable, potentially making it difficult to detect significant differences between treatments. Also, there could have been a bias in the methods used in the current study if unparasitised and parasitised larvae behaved differently. For instance, some parasitised larvae may have dropped to the ground to pupate, therefore not being recovered during this investigation, and dispersal rates may differ between parasitised and unparasitised larvae. There is no information available on this aspect and protocols have been set up to investigate it. Methods used in 1999 field investigations now involve the release of leafroller eggs in sleeves, as in 
this research, but released larvae are recovered after two and four weeks. They are then reared individually on artificial diet and the proportion subsequently parasitised is recorded (Irvin, unpublished). Information is also not available on density dependent searching by $D$. tasmanica but any such effects should have been minimised in the current study because a fixed number of larvae were released on each occasion.

The longevity of both female and male $D$. tasmanica was significantly lower in the water-only treatment compared with all other floral treatments. This was similar to the results of Baggen et al. (1998) who found that longevity of Copidosoma koehleri Blanchard, parasitoid of potato moth, Phthorimaea operculella (Zeller), was significantly increased when adults were caged on flowering plants of dill (Anethrum graveolens L.), borage (Borago officinalis L.) and coriander compared with these plant species without flowers.

Longevity of female and male $D$. tasmanica on the honey/water solution was greater than all other floral treatments. This may be due to this solution being a constant food source, in contrast to the plant material, which may have deteriorated during the experiment. This suggests honey and water may be a suitable resource for D. tasmanica longevity when culturing this species, however, to be certain, its influence on fecundity would also have to be determined.

For male D. tasmanica, a combination of buckwheat and coriander gave a significantly greater longevity than either species on their own. The provision of two pollen and nectar sources may further enhance parasitoid longevity possibly by providing a wider range of amino acids and proteins required by the parasitoid. Field trials need to be conducted to determine whether a combination of two different flowering species in an orchard's understorey further enhances parasitism by D. tasmanica or influences leafroller abundance.

A further question arises as to whether providing buckwheat in the orchard understorey influences other factors of parasitoid 'fitness'. For example, Baggen et al. (1998) showed that $C$. koehleri fecundity was increased in the presence of honey. To investigate this aspect, the current research 'no-choice' laboratory experiment is being modified, using additional floral treatments and renewing plant material more regularly to provide a constant nectar and pollen supply. Measurement of parasitoid fecundity will also be undertaken.

Current herbicide practices in orchards remove potential floral resources, therefore there is a need to reconsider these resources if leafroller parasitoid abundance is to be enhanced. Not only does adding floral resources into the orchard attract parasitoids to the orchard (Irvin et al., in press) but current research suggests that enhancing longevity is another mechanism involved in adding to increased parasitoid populations. The challenge that remains is to determine whether conservation biocontrol can enhance leafroller parasitism to an extent which reduces leafroller populations to below economic thresholds for local and export apple markets.

\section{ACKNOWLEDGEMENTS}

We thank the Agricultural and Marketing Research Development Trust (AGMARDT), New Zealand and Lincoln University, New Zealand for financial support and Keith MacIntosh, Lincoln University for his assistance in trial establishment and maintenance. We are also grateful to Graham Burnip and Max Suckling, of HortResearch for advice and support.

\section{REFERENCES}

Baggen, L.R., Gurr, G.M. and Meats, A., 1998. The influence of food on Copidosoma koehleri (Hymenoptera: Encyrtidae), and the use of flowering plants as a habitat management tool to enhance biological control of potato moth, Phthorimaea operculella (Lepidoptera: Gelechiidae). Biol. Control 11: 9-17.

Batchelor T.A., Walker, J.T.S., Manktelow, D.W.L., Park, N.M. and Johnson, S.R., 1997. New Zealand Integrated Fruit Production for pipfruit - Charting a new course. Proc. 50th N.Z. Plant Prot. Conf:: 14-19. 
Bugg, R.L., Ellis, R.T. and Carlson, R.W., 1989. Ichneumonidae (Hymenoptera) using extrafloral nectar of Faba Bean (Vicia faba L., Fabaceae) in Massachusetts. Biol. Agric. Hort. 6: 107-114.

Irvin, N.A., Wratten, S.D. and Frampton, C.M. Understorey management for the enhancement of the leafroller parasitoid (Dolichogenidea tasmanica Cameron) in Canterbury, New Zealand orchards. Proc. 4th Inter. Hymenopterists' Conf., January 1999, Canberra. CSIRO Publications. (in press).

Kaplan, E.L. and Meier, P., 1958. Non parametric estimation from incomplete observations. Am. Statistical Assoc. J. : 457-481.

Landis, D.B., Wratten, S.D. and Gurr, G.M. Habitat manipulation for natural enemies. Annal Review of Entomology. (in press).

Lovei, G.L., Hodgson, D.J., MacLeod, A. and Wratten, S.D., 1993. Attractiveness of some novel crops for flower-visiting hoverflies (Diptera: Syrphidae): Comparisons from two continents. Pp 368-370 In: Pest Control and Sustainable Agriculture, S. Corey, D. Dall and W. Milne (Eds); CSIRO Publications, Australia.

Penman, D.R., 1984. Deciduous fruit tree pests. Pp 33-49 In: New Zealand Pests and Beneficial Insects, R.R. Scott (Ed); Lincoln University College of Agriculture, Caxton Press.

Stephens, M.J., France, C.M., Wratten, S.D. and Frampton, C., 1998. Enhancing biological control of leafroller (Lepidoptera: Tortricidae) by sowing buckwheat (Fagopyrum esculentum) in an orchard. Biocont. Sci. and Tech. 8: 547-558.

Walker, J. T. S., Baynon, G. T. and White, V., 1991. Insect control on apples with RH5992, a novel insect growth regulator. Proc. 44th N.Z. Plant Prot. Conf: 66-69.

Wearing, C.H., 1998. Cross resistance between azinphosmethyl and tebufenozide in the greenheaded leafroller, Planotortrix octo. Pesticide Sci. 54: 204-211.

Wratten, S.D., Wearing, H., King, D. and Davis, S., 1998. Market-driven IPM in New Zealand - has it delivered? Proc. 6th Australasian Appl. Entomol. Res. Conf. Brisbane, Australia: Pest Management - Future challenges, September 1998 1: 153-159. 